Todos los temas fueron seguidos de animadas preguntas y coloquios, y en muchos de ellos se proyectaron diapositivas o filmes de la materia tratada.

El viernes 26 los asistentes fueron invitados a un almuerzo en el Puerto de Somosierra, con el fin de visitar después las obras que se realizan del kilómetro 100 al 143 de la carretera general de Irún y mostrarles la moderna maquinaria que se emplea y la organización de la obra.

Se solicitó de los asistentes sugerencias y temas para tratar en la segunda semana, con el fin de documentar debidamente las reuniones.

En la organización del ciclo, así como en múltiples detalles de comodidad, agrado y urelaciones públicas», colaboró incansablemente, y con todo el equipo del Instituto Técnico de la Construcción y del Cemento, en cuyos locales se celebraron las reuniones, el Ingeniero don José Pérez Pozuelo.-JuLIán GIMÉNEZ ARRIBAS.

\title{
II. INFORME ANUAL DE LOS CENTROS DIRECTIVOS DEL MINISTERIO DE LA GOBERNACION
}

\section{Introd ucción}

Uno de los corolarios de la aplicación de los principios de economía, celeridad y eficacia a la Administraclón pública viene representado por la necesaria inciusión de estudios sobre los costes y rendimientos de los servicios en las Memorias que Ios Jefes eleven a sus superiores.

Como exponente de esta preocupación, el artículo 16-5 de la Ley de Régimen Jurídico de la Administración del Estado estableció que los Directores generales elevarian anualmente al Ministro un informe acerca de la marcha, coste y rendimiento de los servicios a su cargo. La trascendencia de estos informes anuales es indudable, ya que a su través puede vislumbrarse cuáles.son la eficacia y el ritmo de trabajo de toda la Administración. La Memoria o informe anual, por otra parte, no sólo tiene el natural significado de medio de información al Ministro, sino que también representa un punto de partida muy estimable en la programación de la actividad del Ministerio y eficaz instrumento para la coordinación y mejoramiento de sus servicios.

\section{Normalización de los informes anuales}

Con la finalidad de desarrollar adecuadamente el precepto de la Ley de Régimen Juridico transcrito por la Secretaria General Técnica de la Gobernaclón, se redactó un proyecto de instrucclones, encaminadas a normalizar èl contenido y la presentación del informe o Memoria anual que las Direcciones Generales y Servicios equiparados a las mismas de dicho Ministerio deben elevar al excelentísimo señor Ministro del Departamento. 


\section{Sumario}

Con arreglo al Sumario de referencia, los informes o memorias anuales de los Centros directivos del Ministerio de la Gobernación deben adoptar el contenido y forma siguientes:

\section{A) Contenido.}

1. Primera parte.-El campo objeto de la acción.

El Centro directivo efectuará libremente la distribución de esta primera parte en capítulos y secciones, con arreglo a la sistemática que considere más adecuada a su contenido, el cual consistirá en la descripción del campo de la vida nacional que constituye el objeto de la acción del Centro, expresando la situación, características y fenómenos más importantes producidos en este campo durante el año transcurrido, según los datos recogidos y su valoración. A título de ejemplo se consigna en el sumario el posible contenido de esta primera parte en las Memorias de las Direcciones Genetales de Sanidad y Correos y Telecomunicación.

2. Segunda parte.-La acclón administrativa y los órganos que la ejercen:

Se subdivide, a su vez, en los siguientes capitulos:

2.1. Actividades ejercidas por el Centro directivo sobre el campo descrito en la primera parte: volumen, significación y valor de las mismas, clasificadas en actividades normativas (2.1.1.); actos juridicos individualizados: constitutivos o declarativos, de control, tutela o protectorado y correctivos o represivos (2.1.2.); operaciones técnicas o materiales de gestión: de fomento, impulso, prevención, propaganda, de prestaclón efectiva de servicio y de vigilancia, fiscalización o inspección (2.1.3), y actividades especiales no susceptibles de encaje en cualquiera de los apartados anteriores (2.1.4.).

2.2. Actividades ejercidas por o a través de órganos más o menos descentralizados, dependientes del Centro directivo, que han cooperado durante el año a la acción del mismo. Respecto de cada órgano se expresarán sintéticamente los siguientes extremos:

a) Su naturaleza, a la vista de la Ley de.26 de diciembre de 1958 (disposición transitoria $5 .^{\text {a-1 }}$ ).

b) Carácter y volumen de las actividades realizadas durante el año.

c) Importe de su presupuesto y fuentes de ingresos de que dispone.

d) Clase y número de puestos de trabajo y condición de los titulares de los mismos (funcionarios o no funcionarios); $\mathrm{y}$

e) Calificación que puede merecer su rendimiento y colaboración durante el año.

2.3. Actividades de otros órganos, no dependientes del Centro informante, que también hayan ejercido durante el año actividades sobre el mismo cam. 
po: enumeración, naturaleza y encuadramiento (2.3.1.); actividades ejercidas por cada uno mejor conocidas por el informante (2.3.2.); coordinación lograda e interferencias producidas (2.3.3.); coordinación con organismos internacionales (2.3.4.).

2.4. La vida interna del propio Centro directivo en la organización central y periférica (2.4.1.), en los medios materiales (2.4.2.) y en los personales (2.4.3.), consignándose las apreciaciones sobre la adecuación de la organización y de los medios disponibles a los fines encomendados al Centro y sobre el rendimiento general obtenido (2.4.4.).

3. Tercera parte. $-\mathrm{El}$ coste de los servicios en el Centro directivo y en los órganos descentralizados dependientes del mismo.

Consta de dos capitulos:

3.1. Gastos totales durante el año, con cargo a créditos figurados en los Presupuestos Generales del Estado: personal (3.1.1.); material de oficina, entretenimiento y alquileres de locales arrendados (3.1.2.); adquisiciones, obras, publicaciones, etc. (3.1.3.); subvenciones, auxilios y participaciones en ingresos (3.1.4.); atenciones financieras (3.1.5); inversiones no productoras de ingresos (3.1.6.); inversiones productoras de ingresos (3.1.7.).

3.2. Gastos totales durante el año, con cargo a fondos extrapresupuestarios. En la exposición de los mismos se seguirán, a ser posible, los mismos conceptos que en el anterior apartado.

4. Cuarta parte.-La función especifica de mando.

Queda integrada esta parte cuarta por cuatro capitulos:

4.1. Objetivos propuestos al comenzar el año transcurrido sobre actividades del propio Centro (4.1.1.) y de órganos descentralizados, dependientes del mismo (4.1.2.), sobre coordinaclón y sincronización con las actividades que ejercen otros órganos de la Administración directa o indirectamente respecto al mismo tiempo (4.1.3.) y sobre la organización y medios del Centro informante (4.1.4.).

4.2. Nuevos objetivos propuestos durante el transcurso del año, sobre los mismos aspectos del apartado anterior.

4.3. Valoración comparativa de las realizaciones conseguidas en relación con los objetivos propuestos, con expresión, a ser posible, de los factores favorables o desfavorables que han podido influir en el mayor o menor grado de los logros.

4.4. Objetivos o programas de acción subsistentes o trazados para el año entrante, sobre los distintos aspectos indicados en el apartado 4.1.

5. Quinta parte.-Anexos (datos, estadísticas, organigramas y demás documentos que se estime conveniente). 


\section{B) Forma.}

Hojas y escritura.-Se utilizarán hojas de formato UNE, A4 $(210 \times 297 \mathrm{~mm}$.), y la escritura, a máquina por una sola cara, será a línea cerrada (a un solo espacio), dejándose dos espacios para los puntos y aparte.

Paginación.-Se verificará consignando en el ángulo superior derecho de la hoja la clave de la sección que se reseña en la misma. Cada sección (clave de tres cifras) habrá de comenzar en hoja aparte, y si una sola sección ocupase varias hojas, a continuación de la clave de la sección se escribirá, separado por un guión, el número correlativo que corresponda.

Anexos.-Las hojas y documentos de los anexos se acomodarán al tamaño citado y se paginarán con arreglo al mismo criterlo, utilizando la clave del capítulo a que corresponda el respectivo anexo.

Formato.-La Memoria se remitirá sin encuadernación; cada parte constituirá un folleto independiente.-GuILLERMo FERNándEz. 